EXTENDED REPORT

\title{
Human corneal equivalent as cell culture model for in vitro drug permeation studies
}

\section{S Reichl, J Bednarz, C C Müller-Goymann}

See end of article for authors' affiliations .....................

Correspondence to: Prof Dr C C MüllerGoymann, Institut für Pharmazeutische Technologie TU Braunschweig, Mendelssohnstr. 138106 Braunschweig, Germany; C.Mueller-Goymann@ tu-bs.de

Accepted for publication 1 September 2003

\begin{abstract}
Aims: For the study of transcorneal in vitro permeation of ophthalmic drugs, excised animal cornea or corneal epithelial cell culture are frequently used as a replacement for the human cornea. The main purposes of this study were to reconstruct a complete human organotypic cornea equivalent, consisting of all three different cell types (epithelial, stromal, and endothelial); to test the barrier function of this bioengineered human cornea using three different model drugs (pilocarpine hydrochloride (PHCl), befunolol hydrochloride (BHCl), and hydrocortisone $(\mathrm{HC})$ ); and to determine its usefulness as an in vitro model for prediction of ocular drug absorption into the human eye.

Methods: A multilayer tissue construct was created step by step in Transwell cell culture insert using SV-40 immortalised human endothelial and epithelial cells and native stromal cells (fibroblasts). Morphology was characterised by light microscopy using routine H\&E staining. Scanning electron microscopy was used to evaluate ultrastructural features. Ocular permeation of drugs across the human cornea construct was tested using modified Franz cells and compared with data obtained from excised porcine cornea and previously described porcine cornea constructs.

Results and conclusion: The cornea construct exhibited typical corneal structures such as a monolayer of hexagonally shaped endothelial cells and a multilayered epithelium consisting of seven to nine cell layers with flat superficial cells. The formation of microplicae and microvilli was also confirmed. The human cornea construct showed similar permeation behaviour for all substances compared with excised porcine cornea. However, permeability (permeation coefficients $\mathrm{K}_{\mathrm{p}}$ ) of the human cornea equivalent $(\mathrm{PHCl}$

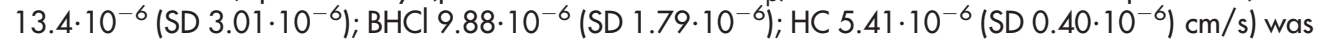
about 1.6-1.8 fold higher than excised porcine cornea. Compared with data from the porcine cornea construct the cultivated human equivalent showed a decreased permeability. The reconstructed human cornea could be appropriate to predict drug absorption into the human eye.
\end{abstract}

$l^{n}$ n vitro permeation studies play an important role in discovery, development, and selection of new ophthalmic drugs or drug delivery systems for application to the eye. As the cornea is the main barrier for the transport of substances into the eye, ${ }^{1-3}$ in vitro permeability studies are usually performed using isolated corneal tissue mounted in modified side by side diffusion chambers. Excised cornea from slaughtered animals or laboratory animals are usually used, ${ }^{4}$ in particular from rabbits, although anatomical and physiological differences between the rabbit and human eye suggest that in vitro permeation data could also differ. ${ }^{36}$ Therefore predictability regarding drug absorption into human eyes is quite difficult.

However, to avoid animal experiments with their various disadvantages-for example, high numbers of animals needed, high costs of laboratory animals, and interindividual differences in permeability, and to establish standardised and competitive in vitro test systems, several in vitro models based on cell culture techniques have been created over the past decade. These models proved to be helpful in the rapid testing of the permeability and drug transport of new substances or formulations ${ }^{7-9}$ in studies about uptake or metabolism of drugs in corneal cells, ${ }^{10}$ or in toxicity studies. ${ }^{11-14}$

The cornea, a multilayered tissue, is made up of three major cellular layers, the epithelium, the stroma, and the endothelium. In previous in vitro permeation studies cell culture models were described using epithelial ${ }^{15}{ }^{16}$ or epithelial and stromal cells. ${ }^{17}$ Furthermore the usefulness of bovine and porcine cornea constructs including all three cell types for in vitro permeation has been shown recently. ${ }^{18-21}$ The aim of the present contribution was (1) to establish a complete organotypic human cornea equivalent including all corneal cell types, (2) to investigate morphological comparability with excised corneal tissue, and (3) to test drug permeability using three ocular model drugs with different physicochemical properties.

All three different human corneal cell types, in this case immortalised epithelial (CEPI 17 CL 4), native stromal (fibroblasts), and also immortalised endothelial (HENC) cells, were cultivated under standard conditions. Cornea was reconstructed with epithelial cells cultivated on stromal cells embedded in a collagen matrix with an underlying layer of endothelial cells. ${ }^{22}$ The construct was investigated regarding typical corneal features by light and scanning electron microscopy. Pilocarpine hydrochloride $(\mathrm{PHCl})$, hydrocortisone $(\mathrm{HC})$, and befunolol hydrochloride $(\mathrm{BHCl})$ were chosen as the three model substances for permeation studies because they are frequently used ophthalmic drugs in the treatment of glaucoma and inflammatory diseases. Permeation data obtained with human cornea construct (HCC) were compared with those from excised porcine cornea and a recently described porcine cornea construct. ${ }^{19-21}$

In the present study we report the engineering of a complete organotypic human cornea construct and, in what we believe to be the first time, discuss the usefulness of such a complete human cornea construct as an alternative to excised cornea for in vitro permeation studies.

Abbreviations: $\mathrm{BHCl}$, bifunolol hydrochloride; $\mathrm{HC}$, hydrocortisone; $\mathrm{HCC}$, human cornea construct; $\mathrm{PHCl}$, pilocarpine hydrochloride 


\section{MATERIAL AND METHODS Materials}

Borocarpin S 2\% from Dr Winzer (Olching, Germany) containing $2 \%$ pilocarpine hydrochloride $(0.01 \%$ benzalkonium chloride as preservative) and Glauconex $0.5 \%$ (AlconPharma, Freiburg, Germany) containing $0.5 \%$ befunolol hydrochloride $(0.007 \%$ benzalkonium chloride) are commercial aqueous eye drop solutions. HC $0.02 \%$ OK is an aqueous solution of $0.02 \%$ hydrocortisone.

\section{Cell culture}

For the isolation of primary fibroblast cultures, human corneal scleral rings were received from the cornea bank, Hannover, Germany. To obtain corneal fibroblasts, both endothelial and epithelial sheets as well as scleral tissue were dissected off. The stroma was cut into small pieces and $3 \mathrm{~mm}$ explants were attached to a $100 \mathrm{~mm}$ diameter plastic dish (Costar, Fernwald, Germany). Fibroblasts showed outgrowth after 6-7 days. Dulbecco's modified Eagle's medium DMEM supplemented with $10 \%$ fetal calf serum FCS, 4 mM L-glutamine and $1 \%$ antibiotic/antimycotic solution (PAA Laboratories, Linz, Austria) were used as growth medium for the stromal cells.

The immortalisation of primary human corneal epithelial cells by a recombinant simian virus (SV) 40 T-antigen retroviral vector defective for viral replication, as well as characterisation of the transfected cells, has been described earlier. ${ }^{13}$ Cells of this cell line (CEPI 17 CL 4) from passage 29 to 37 were used. The CEPI cells were grown in gelatine type A (Sigma, Deisenhofen, Germany) coated tissue culture flasks (Costar), in a 1:1 medium mixture (DMEM/F12) of DMEM (ICN, Eschwege, Germany) and Ham's F12 (Gibco BRL Life Technologies, Karlsruhe, Germany) supplemented with 5\% FCS, $5 \mu \mathrm{g} / \mathrm{ml}$ insulin, $1.4 \mu \mathrm{M}$ hydrocortisone, $1 \mathrm{ng} / \mathrm{ml}$ epidermal growth factor EGF (Biochrom, Berlin, Germany), $10 \mu \mathrm{g} / \mathrm{ml}$ transferrin (Biofluids Biosource International, Nivelles, Belgium), 2 mM L-glutamine, and $1 \%$ antibiotic/ antimycotic solution (Gibco BRL).

Human corneal endothelial cells were isolated from organ cultured cornea and then cultivated as described elsewhere. ${ }^{23}$ Cells were immortalised by transfection with a plasmid encoding SV40 T-antigen using an electroporation method. ${ }^{24}$ These immortalised cells (HENC) were cultivated in medium F99, a 1:1 medium mixture of Ham's F12 and Medium 199 (Gibco BRL) supplemented with 5\% FCS (Biochrom) and 1\% antibiotic/antimycotic solution (Gibco BRL).

All cultures were maintained in $25 \mathrm{~cm}^{2}$ tissue culture flasks (Costar) under standard conditions at $37^{\circ} \mathrm{C}$ in a humidified atmosphere containing $5 \% \mathrm{CO}_{2}$. Growth medium was replaced three times per week.

\section{Human cornea construct-HCC}

Cornea equivalent was constructed step by step in Transwell (Costar) cell culture inserts as described before. ${ }^{19} 2 \cdot 10^{5}$ endothelial cells (HENC) were seeded onto a polycarbonate filter (surface area, $4.7 \mathrm{~cm}^{2}$; pore size, $3.0 \mu \mathrm{m}$ ) covered with a layer of type I collagen, acid extracted from rat tail, and grown to confluence within 7 days in medium F99. A type I collagen gel matrix containing $6 \cdot 10^{4}$ stromal fibroblasts was then cast on top of the confluent endothelial cell layer. Endothelium stroma equivalent was cultivated approximately 4 days submerged in DMEM medium. $1.5 \cdot 10^{5}$ epithelial cells (CEPI 17 CL 4) were seeded onto the contracted collagen lattice and grown in medium DMEM/ F12 for additional 7 days submerged to confluence. After epithelium became confluent, tissue construct was lifted to the air-liquid interface for an additional 10 days and cultivated in medium DMEM/F12 with a reduced serum content of $2 \%$. Within ten days a multilayered epithelium was formed. The cultures were maintained in a humidified incubator at $37^{\circ} \mathrm{C}$ with $5 \% \mathrm{CO}_{2}$ and medium was also replaced three times per week.

\section{Light microscopy}

Tissue was fixed in a $75 \mathrm{mM}$ phosphate buffer $\mathrm{pH} 7$ containing $3.5 \%$ formaldehyde, dehydrated in isopropyl alcohol, and embedded in paraffin. Cross sections of $4 \mu \mathrm{m}$ were cut, stained in hematoxylin eosin and examined with a photomicroscope Olympus IX50 (Olympus, Hamburg, Germany).

\section{Scanning electron microscopy}

Samples were fixed with $1.5 \%$ paraformaldehyde, 3\% glutaraldehyde, $1.5 \%$ acrolein in $0.2 \mathrm{M}$ cacodylate buffer ( $\mathrm{pH} 7.2$ ) for $24 \mathrm{~h}$ at $20^{\circ} \mathrm{C}$, treated with $2 \%$ glycine, sodium glutamate, sucrose $(\mathrm{pH} 6.2)$ for $12 \mathrm{~h}$ at $20^{\circ} \mathrm{C}$, then with $2 \%$ tannic acid $\mathrm{pH} 4$ for $12 \mathrm{~h}$ at $20^{\circ} \mathrm{C}$, rinsed in $\mathrm{H}_{2} \mathrm{O}$ and postfixed with $2 \%$ osmium tetroxide for $12 \mathrm{~h}$ at $20^{\circ} \mathrm{C} .{ }^{25}$ Tissue equivalent was dehydrated in a graded series of isopropyl alcohol and sputtered with gold particles before examination in a Stereoscan 250 (Cambridge Instruments, Cambridge, UK) scanning electron microscope.

\section{Permeation studies}

Diffusion experiments for the evaluation of transcorneal drug permeability from three aqueous solutions containing model drugs ( $\mathrm{PHCl}, \mathrm{HC}, \mathrm{BHCl}$ ) were performed for 420 minutes using modified Franz diffusion cells at $37^{\circ} \mathrm{C}$. To compare the barrier function, both excised porcine cornea and organotypic human cornea construct were used. The donor drug formulations used were Borocarpin S 2\%, HC 0.02\% OK and Glauconex $0.5 \%$ as described above. The receiver solution contained isotonic phosphate buffered saline $\mathrm{pH} 7.4$ and was stirred with a magnetic stirrer (Janke\&Kunkel, Staufen, Germany) at $400 \mathrm{rpm}$ during the experiment. Samples were taken from the receiver chamber at fixed time intervals (every $60 \mathrm{~min}$ ) and quantitatively analysed by high performance liquid chromatography (HPLC).

The permeation parameters of model drugs were calculated by plotting the amounts $\left(\mu \mathrm{g} / \mathrm{cm}^{2}\right)$ of drug permeated through the excised cornea or cornea construct versus the time (minutes). The permeation coefficient $\mathrm{K}_{\mathrm{P}}$ was calculated as flux/drug concentration from the linear ascent of a permeation curve.

\section{HPLC methodology}

Concentrations of model drugs in the samples were determined using a Waters 515, 717 plus, 486 HPLC system (Waters, Eschborn, Germany) at ambient temperature, using columns of Gromsil 120 ODS-3 CP $5 \mu \mathrm{m}, 125 \times 4 \mathrm{~mm}$ (Grom, Herrenberg, Germany) in the case of pilocarpine hydrochloride and befunolol hydrochloride, while a column of Hypersil ODS $5 \mu \mathrm{m} 250 \times 4 \mathrm{~mm}$ was used for hydrocortisone. The standard HPLC methods used for pilocarpine hydochloride, befunolol hydrochloride, and hydrocortisone have already been described earlier. ${ }^{19} 2121 a$ Data analysis and calculation were performed by Waters Millenium 32 Chromatography Manager software (Waters).

\section{RESULTS}

\section{Corneal cells}

Native human fibroblasts were obtained by standard outgrowth technique. Purity of cell population was ensured by specific isolation method and indicated by typical fibroblastoid appearance of cells. Stromal cells in culture are elongated and spindle shaped as shown in figure 1B. Cells showed a good proliferation rate and could be cultivated for 10 passages without any change of their typical morphology. 

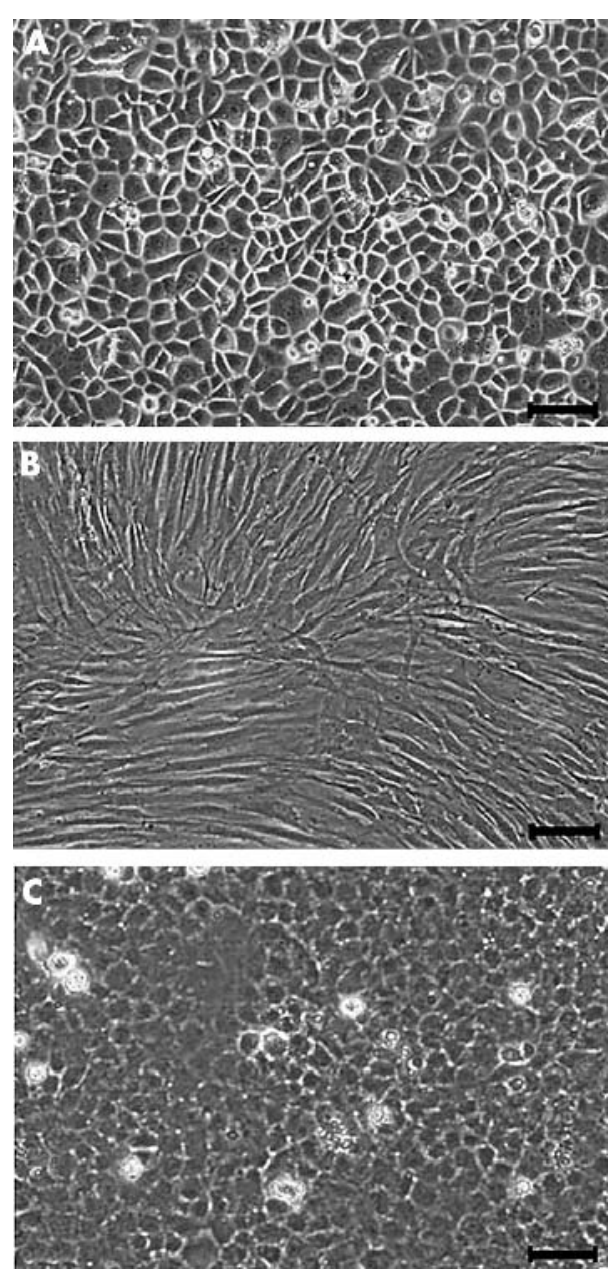

Figure 1 Phase-contrast micrographs of the three different cornea cell types. (A) Confluent monolayer of CEPI $17 \mathrm{CL} 4$ cells showing typical cobblestone morphology (scale bar $=100 \mu \mathrm{m}$ ). (B) Morphological appearance of primary culture of stromal cells. Fibroblasts are elongated and spindle shaped. Scale bar $100 \mu \mathrm{m}$. (C) Monolayer of HENC cells exhibiting typical hexagonal shape. Scale bar $50 \mu \mathrm{m}$.

The SV-40 transformed endothelial (HENC) and epithelial (CEPI) cells are well characterised immortalised cell lines ${ }^{13} 24$ and show a high proliferation rate. HENC showed morphological similarities to endothelial cells in vivo and were able to form a tight monolayer of hexagonally shaped cells (fig lC) which closely resemble human corneal endothelium in vivo. The morphological and functional properties of these cells after transplantation onto donor corneas have been described before. ${ }^{26}$ Furthermore CEPI expressed the cobblestone like pattern which is characteristic of corneal epithelial cells in culture. Figure lA shows a monolayer of polygonally shaped epithelial cells.

\section{Cornea equivalent}

The in vitro cornea was assembled in Transwell culture insert to ensure both a submerged cultivation and a differentiation of multilayered epithelium by growth at the air-liquid interface. The completely grown bio-engineered human cornea construct (HCC) consisted of a stroma equivalent containing native fibroblasts, an underlying endothelium, and a stratified epithelium on top derived from HENC and CEPI 17 CL 4 respectively. Figure 2 shows different phases in the stepwise reconstruction of HCC. After seven days of cultivation, a confluent monolayer of endothelial cells grown on collagenous sheet occurred. A tight mosaic like pattern of
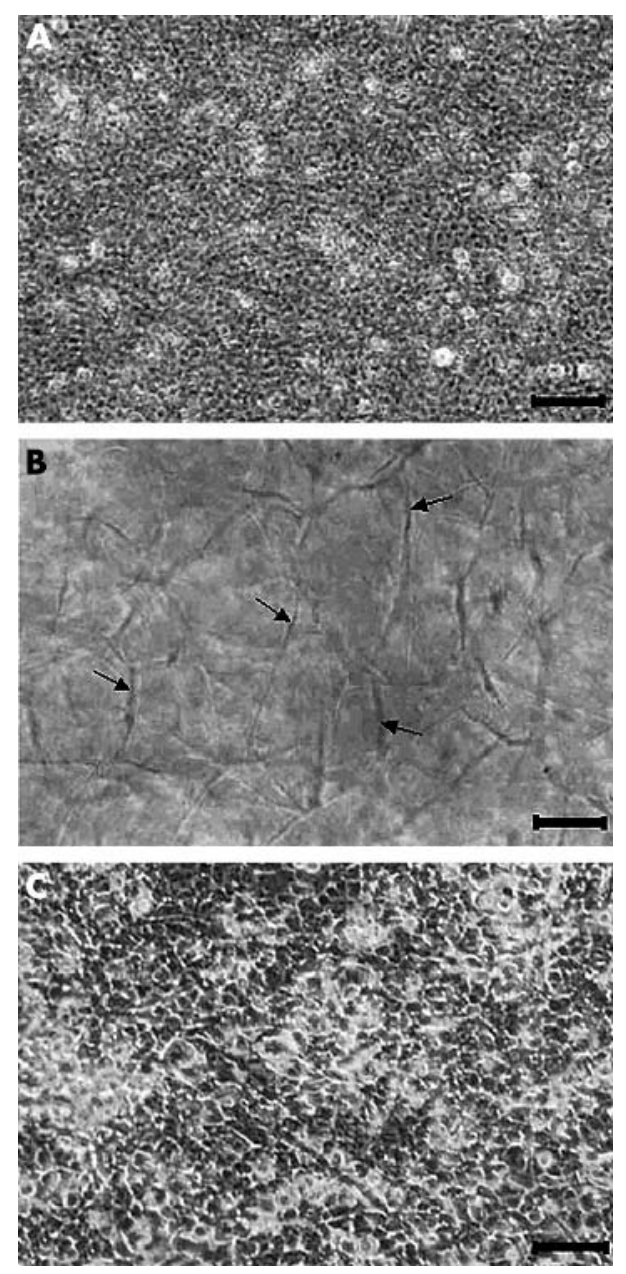

Figure 2 Phase contrast micrographs of different phases in the stepwise reconstruction of HCC (scale bar $=100 \mu \mathrm{m}$ ). (A) Tightly packed monolayer of hexagonally shaped endothelial cells as also found in vivo. (B) Fibroblasts incorporated into the collagenous stroma equivalent. Cells become elongated and spread out (arrows). (C) CEPI $17 \mathrm{CL} 4$ cells cultured on stroma biomatrix exhibiting polygonal shapes.

hexagonally shaped endothelial cells was clearly visible (fig 2A). The morphology of cultured endothelial monolayer was similar to the typical structure of human corneal endothelium in vivo. Within a further 4-5 days the stroma equivalent was cultivated consisting of fibroblasts embedded in a collagen gel. Within 1-3 days of cultivation, contraction of gel depending on collagen concentration and number of cells was observed, as well as spreading out of the stromal cells in the collagen lattice (fig 2B). After seeding of epithelial cells on stroma biomatrix and cultivation for additional seven days light microscopy analysis indicated that cultured corneal epithelial cells on the biomatrix had formed a tight monolayer (fig 2C).

For expression of a multilayered epithelium, the cornea construct was cultivated at air-liquid interface and microscopic examination of hematoxylin and eosin (H\&E) stained cross sections of HCC were performed after ten further days of cultivation. Figure 3B shows the superior part of human cornea construct consisting of stratified epithelium grown on stroma equivalent. A tightly packed epithelium of seven to nine cell layers was detectable. The cultivated epithelium closely resembled the corneal epithelium found in porcine cornea in vivo (fig 3A) but in the case of reconstructed epithelium it was difficult to distinguish the basal cells from the wing cells. However, the uppermost cells (superficial cell 

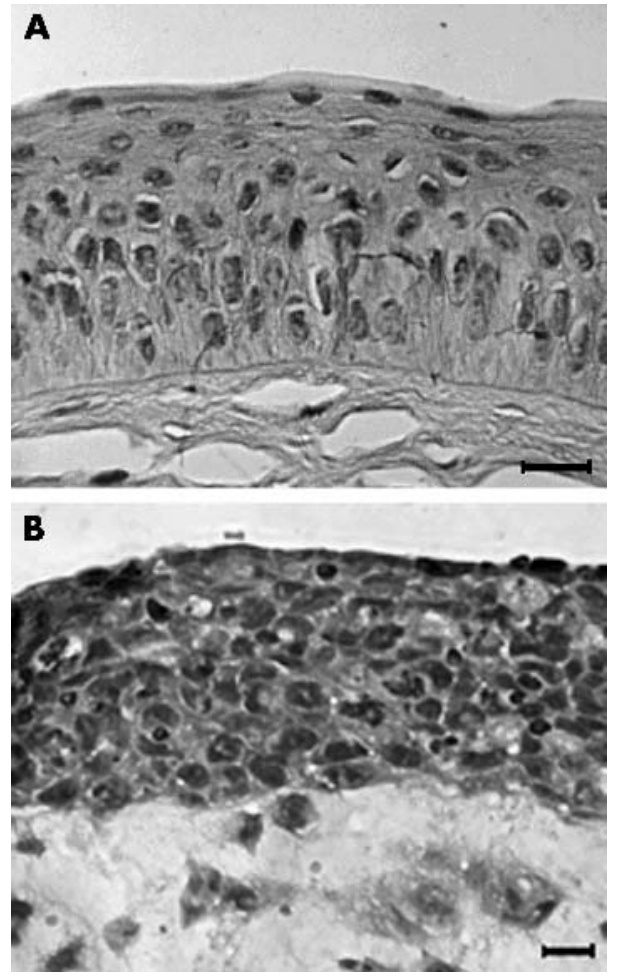

Figure 3 Histological cross sections of $(A)$ original porcine corneal epithelium and (B) cultured human epithelial cells grown on a stroma equivalent and underlying endothelial sheet stained with hematoxylin eosin (scale bar $=25 \mu \mathrm{m}$ ).

layer) appeared flattened as is also the case in vivo. This finding is in agreement with other reconstructed human corneal epithelium containing transformed epithelial. ${ }^{17} 2728$

Scanning electron microscopy experiments also showed similarities in morphology between reconstructed tissue and
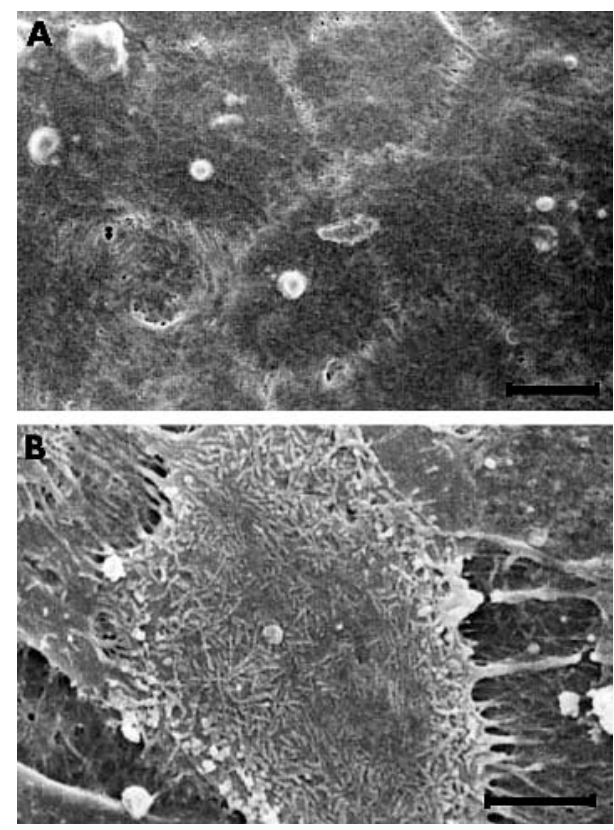

Figure 4 Scanning electron microscopic images of (A) cultured endothelial cells confluent grown on a type I collagen gel (scale bar $=10 \mu \mathrm{m}$ ), and (B) epithelial surface of cornea construct (scale bar $5 \mu \mathrm{m})$.
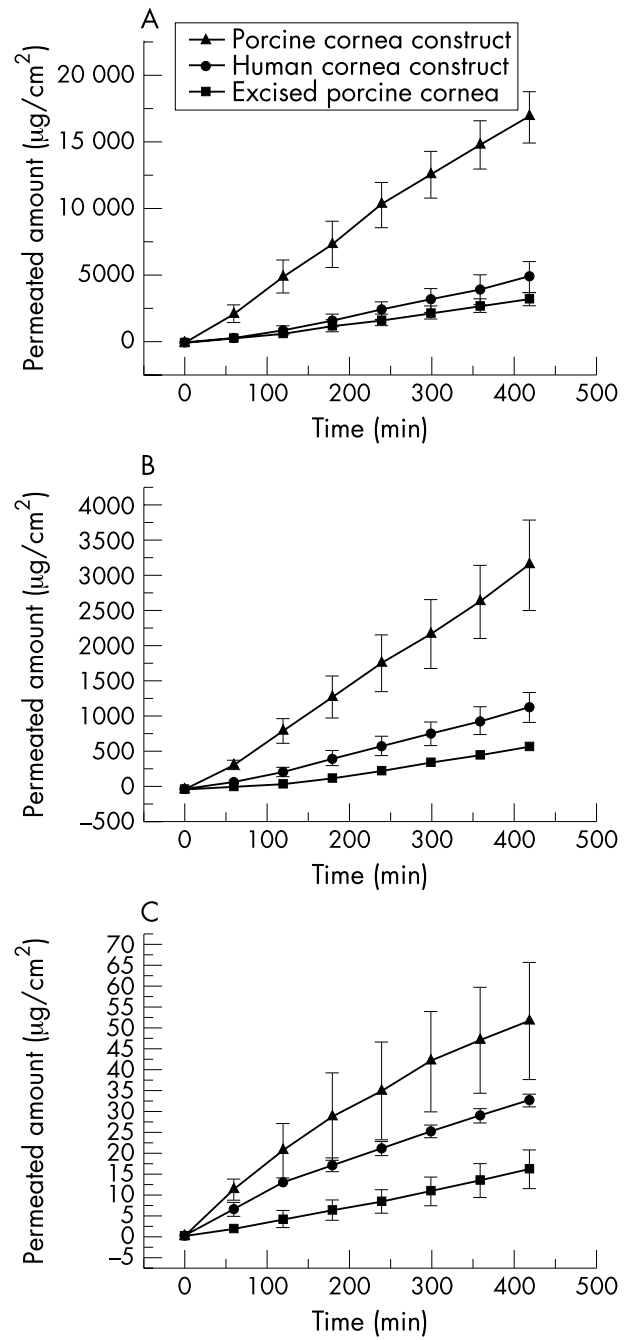

Figure 5 Permeated amounts of (A) pilocarpine hydrochloride (PHCl), (B) befunolol hydrochloride $(\mathrm{BHCl})$, and $(\mathrm{C})$ hydrocortisone $(\mathrm{HC})$ versus time across human cornea construct (HCC), porcine cornea construct, and excised porcine cornea. Each point represents the mean (SD) of 512 determinations.

the cornea in vivo. A confluent monolayer was formed by seeding human endothelial cells onto a collagen gel. The monolayer exhibited a predominantly physiological structural organisation similar to normal human endothelium.

Table 1 Drug permeability of HCC compared with porcine cornea construct and excised porcine cornea. The permeation coefficients $K_{p}(\mathrm{~cm} / \mathrm{s})$ of pilocarpine hydrochloride (Borocarpin S 2\%), befunolol hydrochloride (Glauconex 0.5\%), and hydrocortisone (HC 0.02\% OK), mean (SD) ( $n=5-12)$.

\begin{tabular}{|c|c|c|c|c|}
\hline Donor & $\log P^{*}$ & $\begin{array}{l}\text { Excised } \\
\text { porcine } \\
\text { cornea† }\end{array}$ & $\begin{array}{l}\text { Human } \\
\text { cornea } \\
\text { construct }\end{array}$ & $\begin{array}{l}\text { Porcine cornea } \\
\text { construct† }\end{array}$ \\
\hline $\begin{array}{l}\text { Borocarpin } \\
\text { S 2\% } \\
\text { Glauconex } \\
\text { O.5\% } \\
\text { HC } 0.02 \% \\
\text { OK }\end{array}$ & $\begin{array}{l}-1.3 \\
-0.4 \\
1.6\end{array}$ & $\begin{array}{l}8.57 \cdot 10^{-6} \\
\left(0.53 \cdot 10^{-6}\right) \\
5.95 \cdot 10^{-6} \\
\left(0.52 \cdot 10^{-6}\right) \\
3.07 \cdot 10^{-6} \\
\left(0.99 \cdot 10^{-6}\right)\end{array}$ & $\begin{array}{l}13.4 \cdot 10^{-6} \\
\left(3.01 \cdot 10^{-6}\right) \\
9.88 \cdot 10^{-6} \\
\left(1.79 \cdot 10^{-6}\right) \\
5.41 \cdot 10^{-6} \\
\left(0.40 \cdot 10^{-6}\right)\end{array}$ & $\begin{array}{l}35.6 \cdot 10^{-6} \\
\left(1.53 \cdot 10^{-6}\right) \\
24.8 \cdot 10^{-6} \\
\left(4.79 \cdot 10^{-6}\right) \\
7.11 \cdot 10^{-6} \\
\left(1.21 \cdot 10^{-6}\right)\end{array}$ \\
\hline
\end{tabular}

*Partition coefficients $\mathrm{P}$ between 1 -octanol and the aqueous formulations. †Reichl and Müller-Goymann, 2001a,b; 2003. 
Cells displayed the characteristic hexagonal form and junctional complexes between neighbours appeared well developed (fig 4A). Furthermore figure 4B shows a micrograph of the epithelial surface of HCC. Superficial epithelial cells also formed tight sheets and typical structures such as microvilli and microplicae were visible. But obvious distinctions to the epithelium in vivo were observed. Compared with in vivo epithelium, cultured epithelium exhibited fewer microvilli and microplicae, and the interface between adjacent cells appeared less well defined. In addition cultivated epithelial cells seemed to be less flattened than superficial cells in vivo.

\section{Permeation studies}

In order to investigate the potential of HCC as an in vitro model for transcorneal permeation studies, the permeation of three ophthalmic model drugs was evaluated and compared with that via excised porcine cornea and a previously developed organotypic porcine cornea construct. ${ }^{19-21}$ The permeation profiles of each model drug through different cornea constructs and excised cornea are presented in figure 5 . The resulting permeation coefficients $K_{p}$ were expressed as mean (standard deviation) and are shown in table 1. For all drugs the same permeation ranking with the different corneal tissues was observed. The highest permeability was detectable with the porcine cornea construct. Excised porcine cornea appeared least permeable for the drugs, although differences in permeability towards HCC were fairly small. Furthermore HCC showed distinctly increased barrier properties in comparison with the porcine cornea construct. It should be pointed out that permeability of HCC in comparison with excised porcine cornea was merely increased by factor 1.6 to 1.8 for all three drugs.

\section{DISCUSSION}

Extensive research is being done at present in the field of three dimensional tissue engineering, ${ }^{29}$ as well as in the development of cell culture models of biological barriers as in vitro test systems for drug absorption and delivery. ${ }^{30}$

Corneal epithelial cultures ${ }^{7-9}{ }^{15}{ }^{16}$ or co-cultures of epithelial cells and fibroblasts ${ }^{17}$ have recently been examined in in vitro permeation studies. Furthermore reconstruction of animal corneal tissue has been described..$^{122}{ }^{31-33}$ Griffith et al described for the first time a complete functional human corneal equivalent constructed from cell lines including all three corneal cell types. ${ }^{34}$ To our best knowledge, the use of a complete human cornea equivalent with epithelial, stromal, and endothelial cells in drug permeability studies to assess its usefulness as an in vitro model for prediction of ocular drug absorption, was performed for the first time in this study.

We know from previous investigations regarding cornea reconstruction ${ }^{18} 2122$ that the best results can be obtained by co-culturing each corneal cell type with extracellular matrix, collagen type I, in which epithelial, stromal, and endothelial cells can interact in vitro the same way they do in vivo. Furthermore cultivation at air-liquid interface has a great influence on the development of a strong, interlocked multilayered epithelium. ${ }^{15}$ Considering these facts we were able to reconstruct a human tissue equivalent with histological properties similar to those in cornea in vivo. The epithelium is considered as the main barrier for drug transport across the cornea into aqueous humour. Hence the expression of a full thickness epithelium in HCC suggests that similar barrier properties may also be generated in the tissue equivalent. Despite small ultrastructural differences between construct and original with regard to surface morphology, which may occur due to absence of lacrimal fluid and eye blinking during in vitro cultivation, major aspects such as tightly packed epithelial sheets and flattened interlocked superficial epithelial cells were very similar.

Our results show, for all three model drugs, an increased permeability across cornea constructs in comparison with that across excised porcine cornea with the following tendency: porcine cornea construct $>$ human cornea construct $>$ excised porcine cornea. For the in vitro permeation studies from aqueous drug formulations, an increased permeability across the cornea constructs was not unexpected in so far as increased permeability of in vitro models based on cell culture techniques is frequently described. ${ }^{917-21}{ }^{35}$ However, three different ophthalmic drugs as donors were used in order to examine whether various physicochemical properties of drugs affect the permeation rate across excised cornea and HCC the same way. The Kp values obtained with HCC were in all cases predominantly smaller than those obtained with porcine cornea construct. Moreover there were only small differences in permeation behaviour between HCC and excised porcine cornea by factor 1.6 to 1.8. Not only are these factors fairly small but they are also constant for both hydrophilic ( $\mathrm{PHCl}, \mathrm{BHCl})$ and lipophilic ( $\mathrm{HC}$ ) model drugs. Such a small factor between the in vitro model and original cornea makes the cornea construct a promising tool for prediction of ocular drug absorption. Unfortunately, permeation data from excised human cornea do not exist. Thus, a comparison of such data with our results from HCC is not possible. Nevertheless, previous studies regarding corneal permeation behaviour in vitro using excised cornea from animals suggest that corneal permeability increased with a decreased number of epithelial sheets. ${ }^{45}$ The human cornea consists of 5-6 cell layers ${ }^{36}$ whereas porcine cornea comprises 6-9 layers. ${ }^{37}$ This suggests that the differences between HCC and excised human cornea might be smaller as described above. Therefore further comparative permeation studies with human donor cornea (inappropriate for transplantation), including the same drug formulations as described above and other known drugs for ophthalmological administration, have to be performed to evaluate the degree of comparability and to confirm the postulated similarities between HCC and excised human cornea in terms of their in vitro permeation barrier properties.

As the biology of the porcine eye is close to that of the human one in many respects, ${ }^{38}$ the good comparability of permeation data from human cornea equivalent with data from excised porcine cornea suggests HCC as an appropriate in vitro model for permeation studies. Furthermore HCC should be promising in in vitro toxicological studies. ${ }^{11}{ }^{14}$

\section{ACKNOWLEDGEMENTS}

We would like to thank Nestec (Nestec Ltd, Nestlé Research Center Lausanne, PO Box 44, CH-1000 Lausanne 26, Switzerland) as the source of human corneal epithelial cell line CEPI 17 CL 4.

Furthermore the authors thank Dr E Parussis, Braunschweig, for preparing the sections of the cultures, Arnold Eilmes from the Institute for Animal Science and Animal Husbandry, Braunschweig for the supply of porcine eyes, and Rüdiger Hoche from the Institute for Welding Technology, Technical University of Braunschweig for his support with scanning electron microscopy

\section{Authors' affiliations \\ S Reichl, C C Müller-Goymann, Institut für Pharmazeutische Technologie, Technische Universität Braunschweig, Braunschweig, Germany \\ J Bednarz, Klinik und Poliklinik für Augenheilkunde, Universitätsklinikum Hamburg-Eppendorf, Germany \\ REFERENCES \\ 1 Doane MG, Jensen AD, Dohlmann CH. Penetration routes of topically applied eye medications. Am J Ophthalmol 1978;85:383-86.}


2 Burstein NL, Anderson JA. Corneal penetration and ocular bioavailability of drugs. J Ocular Pharmacol 1985;1:309-26.

3 Lee VH, Robinson JR. Topical ocular drug delivery: recent developments and future challenges. J Ocular Phamacol 1986;2:67-108.

4 Prausnitz MR Noonan JS. Permeability of cornea, sclera and conjunctiva: A literature analysis for drug delivery to the eye. J Pharm Sci 1998;87:1479-88.

5 Scholz M, Schrunder S, Gartner S, et al. Ocular drug permeation following experimental excimer laser treatment on the isolated pig eye. $J$ Ocul Pharmacol Ther 2002;18:177-83.

6 Maurice DM, Mishima S. Ocular Pharmakokinetics. In: Sears ML, ed. Pharmacology of the eye. Berlin: Springer-Verlag, 1984:19-116.

7 Goskonda VR, Khan MA, Hutak CM, et al. Permeability characteristics of novel mydriatic agents using an in vitro cell culture model that utilizes SIRC rabbit corneal cells. J Pharm Sci 1999;88:180-4.

8 Goskonda VR, Reddy IK. Permeability of pure enantiomers of timolol across SIRC rabbit corneal cells. Pharm Pharmacol Commun 1999;5:111-15.

9 Kawazu K, Shiono H, Tanioka H, et al. Beta adrenergic antagonist permeation across cultured rabbit corneal epithelial cells grown on permeable supports. Curr Eye Res 1998;17:125-31.

10 Kawazu K, Yamada K, Nakamura M, et al. Characterization of cyclosporin A transport in cultured rabbit corneal epithelial cells: P-glycoprotein transport activity and binding to cyclophilin. Invest Ophthalmol Vis Sci 1999:40:1738-44.

11 Schneider Al, Maier-Reif K, Graeve T. The use of an in vitro cornea for predicting ocular toxicity. In Vitro Toxicol 1997; 10:309-18.

12 Saarinen-Savolainen P, Jarvinen T, Araki-Sasaki K, et al. Evaluation of cytotoxicity of various ophthalmic drugs, eye drop excipients and cyclodextrins in an immortalized human corneal epithelial cell line. Pharm Res 1998; 15:1275-80.

13 Offord EA, Sharif NA, Mace K, et al. Immortalized human corneal epithelial cells for ocular toxicity and inflammation studies. Invest Ophthalmol Vis Sci 1999:40:1091-101.

14 Clothier R, Orme A, Walker TL, et al. A comparison of three cytotoxicity endpoints in the corneal HCE-T model. ATLA 2000;28:293-302.

15 Chang J, Basu SK, Lee VHL. Air-interface condition promotes the formation of tight corneal epithelial cell layers for drug transport studies. Pharm Res 2000;17:670-76

16 Scholz M, Lin JE, Lee VHL, et al. Pilocarpine permeability across ocular tissues and cell cultures: influence of formulation parameters. J Ocul Pharmacol Ther 2002; 18:455-68.

17 Toropainen E, Ranta V, Talvitie A, et al. Culture model of human corneal epithelium for prediction of ocular drug absorption. Invest Ophthalmol Vis Sci 2001;42:2942-48.

18 Tegtmeyer S, Papantoniou I, Müller-Goymann CC. Reconstruction of an in vitro cornea and its use for drug permeation studies from different formulations containing pilocarpine hydrochloride. Eur J Pharm Biopharm 2001;51:119-25

19 Reichl S, Müller-Goymann CC. Development of an organotypical cornea construct as an in vitro model for permeation studies. Ophthalmologe 2001:98:853-58.

20 Reichl S, Müller-Goymann CC. Cultivation of a porcine organotypic cornea construct and its use for various in vitro permeation studies. Arch Pharm 2001;334(Suppl 2):73.
21 Reichl S, Müller-Goymann CC. The use of a porcine organotypic cornea construct for permeation studies from formulations containing befunolol hydrochloride. Int J Pharm 2003;250:191-201.

21 a Way SE, Hadgraft J. In vitro investigation of the permeation and metabolism of hydrocortisone and hydrocortisone-21-esters. In: Scott RC, Guy RH, Hadgraft J, Boddé HE, eds. Prediction of percutaneous penetration. London: BC Technical Services, 1991;2.

22 Zieske JD, Mason VS, Wasson ME, et al. Basement membrane assembly and differentiation of cultured corneal cells: importance of culture environment and endothelial cell interaction. Exp Cell Res 1994;214:621-33.

23 Engelmann K, Friedl P. Optimization of culture conditions for human corneal endothelial cells. In Vitro Cell Dev Biol 1989;25:1065-72.

24 Bednarz J, Teifel M, Friedl P, et al. Immortalization of human corneal endothelial cells using electroporation protocol optimized for human corneal endothelial and human retinal pigment epithelial cells. Acta Ophthalmol Scand 2000;78:130-36.

25 Fujita T, Tanaka K, Tokunaga J. Zellen und Gewebe: Ein REM-Atlas für Mediziner und Biologen. Stuttgart: Gustav Fischer Verlag, 1986.

26 Aboalchamat B, Engelmann K, Böhnke M, et al. Morphological and functional analysis of immortalized human corneal endothelial cells after transplantation. Exp Eye Res 1999;69:547-53.

27 Kahn CR, Young E, Lee ICH, et al. Human corneal epithelial primary cultures and cell lines with extended life span: in vitro model for ocular studies. Invest Ophthalmol Vis Sci 1993;34:3429-41.

28 Araki-Sasaki K, Ohashi Y, Sasabe T, et al. An SV40-immortalized human corneal epithelial cell line and its characterization. Invest Ophthalmol Vis Sci 1995;36:614-21.

29 Germain L, Carrier P, Auger FA, et al. Can we produce a human corneal equivalent by tissue engineering? Prog Retin Eye Res 2000; 19:497-527.

30 Lehr CM. Cell culture models of biological barriers: in vitro test systems for drug absorption and delivery. London: Taylor \& Francis, 2002.

31 Minami $Y$, Sugihara H, Oono S. Reconstruction of cornea in threedimensional collagen gel matrix culture. Invest Ophthalmol Vis Sci 1993;34:2316-24.

32 Parnigotto PP, Bassani V, Montesi F, et al. Bovine corneal stroma and epithelium reconstructed in vitro: characterisation and response to surfactants. Eye 1998;12:304-10.

33 Schneider Al, Maier-Reif K, Graeve T. Constructing an in vitro cornea from cultures of the three specific corneal cell types. In Vitro Cell Dev Biol Anim 1999;35:515-26.

34 Griffith M, Osborne R, Munger R, et al. Functional human corneal equivalents constructed from cell lines. Science 1999;286:2169-72.

35 Goskonda VR, Hill RA, Khan MA, et al. Permeability of chemical delivery systems across rabbit corneal (SIRC) cell line and isolated corneas: a comparative study. Pharm Dev Technol 2000;5:409-16.

36 Nishida T. Cornea. In: Krachmer JH, ed. Cornea. St Lovis, MO: Mosby, 1997:3-60.

37 Ehlers N. Morphology and histochemistry of the corneal epithelium of mammals. Acta Anat 1970;75:161-98.

38 Pond WG, Houpt KA. The biology of the pig. Ithaca and London: Cornell University Press, 1978. 